\title{
Percutaneous left atrial appendage closure devices: safety, efficacy, and clinical utility
}

\author{
This article was published in the following Dove Press journal: \\ Medical Devices: Evidence and Research \\ 2 September 2016 \\ Number of times this article has been viewed
}

\section{Martin J Swaans \\ Lisette IS Wintgens \\ Arash Alipour \\ Benno JWM Rensing \\ Lucas VA Boersma}

Department of Cardiology, St. Antonius Hospital, Nieuwegein, the Netherlands
Correspondence: Martin J Swaans Department of Cardiology, St. Antonius Hospital, Koekoekslaan I, 3435

Nieuwegein, the Netherlands

$\mathrm{Tel}+31306099111$

Fax +3I 306092274

Emailm.swaans@antoniusziekenhuis.nl

\begin{abstract}
Atrial fibrillation (AF) is the most common arrhythmia treated in the clinical practice. One of the major complications of AF is a thromboembolic cerebral ischemic event. Up to $20 \%$ of all strokes are caused by AF. Thromboembolic cerebral ischemic event in patients with AF occurs due to atrial thrombi, mainly from the left atrial appendage (LAA). Prevention of clot formation with antiplatelet agents and especially oral anticoagulants (vitamin $\mathrm{K}$ antagonists or newer oral anticoagulants) has been shown to be effective in reducing the stroke risk in patients with AF but has several drawbacks with (major) bleedings as the most important disadvantage. Therefore, physical elimination of the LAA, which excludes the site of clot formation by surgical or percutaneous techniques, might be a good alternative. In this review, we discuss the safety, efficacy, and clinical utility of the Watchman ${ }^{\mathrm{TM}}$ LAA closure device.
\end{abstract}

Keywords: stroke, left atrial appendage, prevention, atrial fibrillation

\section{Introduction}

Atrial fibrillation (AF) is the most common arrhythmia treated in the clinical practice. Lifetime risk of AF is estimated to be $24 \%$ in elderly patients. ${ }^{1-3}$ The most devastating complication of AF is a stroke. Patients with AF have a fivefold higher risk of stroke and a twofold increased risk of all-cause mortality. ${ }^{4}$ The overall annual stroke risk is 5\% in patients with AF, which increases up to $15 \%$ in high-risk patients. ${ }^{5}$ The percentage of strokes caused by AF increases with age. It has been estimated that $20 \%-38 \%$ are caused directly by AF ${ }^{5-10}$ Furthermore, the prevalence of nondiagnosed ("silent") AF may in fact lead to a higher attributable risk of AF for ischemic stroke. ${ }^{10}$ AF-related ischemic strokes are associated with significantly higher morbidity, mortality, and health care expenses compared to stroke from other etiologies. ${ }^{11,12}$ Thromboembolic cerebral ischemic event in patients with AF occurs due to the formation of atrial thrombi, especially in the left atrial appendage (LAA). Research has shown that $>90 \%$ of the atrial thrombi find their origin in the LAA. ${ }^{13-16}$ Prevention of clot formation with antiplatelet agents and especially oral anticoagulants (OACs) (vitamin K antagonists [VKAs] or newer oral anticoagulants [NOACs]) has been shown to be effective in reducing stroke risk in these patients but has several drawbacks with (major) bleedings as the most important disadvantage. Therefore, physical elimination of the LAA, which excludes the site of clot formation by surgical or percutaneous techniques, might be a good alternative. 

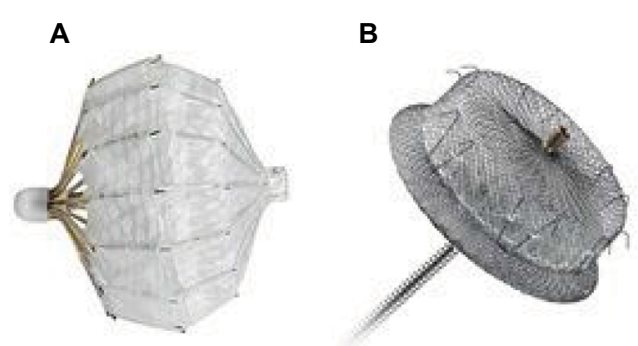

C

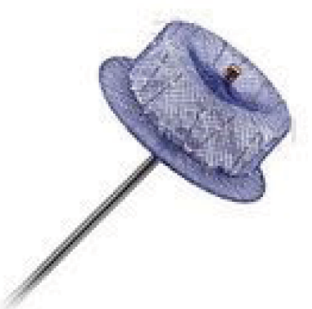

D

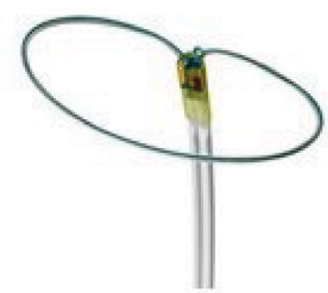

E

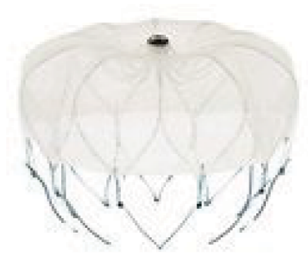

Figure I Percutaneous devices for left atrial appendage closure (LAAC)

Notes: (A) Plaato ${ }^{\mathrm{TM}}$ device. (B) Amplatzer ${ }^{\mathrm{TM}}$ Cardiac Plug. (C) Amplatzer Amulet ${ }^{\mathrm{TM}}$ device. (D) LARIAT. (E) Watchman ${ }^{\mathrm{TM}}$.

Abbreviation: Plaato, Percutaneous Left Atrial Appendage Transcatheter Occlusion.

\section{Devices for percutaneous LAA closure}

Several devices have been proposed to obtain durable LAA closure (LAAC) by means of a percutaneous approach (Figure 1). The first percutaneous LAA occluder proposed was the Percutaneous Left Atrial Appendage Transcatheter Occlusion (Plaato ${ }^{\mathrm{TM}}$; Endovascular 3, Plymouth, MN, USA) device, which was withdrawn from the market in 2006, despite favorable preliminary results in terms of safety and efficacy. ${ }^{17,18}$ The Amplatzer ${ }^{\mathrm{TM}}$ Cardiac Plug (ACP) and its second generation ACP2 or Amplatzer Amulet ${ }^{\mathrm{TM}}$ (St. Jude Medical, St Paul, MN, USA) involve similar implantation techniques and have shown good results in prospective registries in the absence of large-scale randomized clinical trials. ${ }^{19}$ The LARIAT suture delivery device (SentreHEART, Palo Alto, CA, USA) excludes the LAA by ligation through a combination of pericardial and transseptal access. Patients with a history of pericarditis or cardiac surgery are considered ineligible for LARIAT implantation. However, periprocedural (N)OAC therapy is not required in LARIAT implantation. ${ }^{20,21}$

Of all available percutaneous techniques for closure of the LAA, the Watchman ${ }^{\mathrm{TM}}$ device (Atritech, a subsidiary of Boston Scientific, Plymouth, MN, USA) is the best investigated. After this brief outline on earlier percutaneous LAAC devices, this review focuses in detail on the results of clinical trials of LAAC by means of the Watchman device.

\section{Efficacy of percutaneous LAAC}

Table 1 summarizes currently published clinical experience with the Watchman device with regard to efficacy. The initial worldwide experience study showed that LAA occlusion (LAAO) using the Watchman device was safe and feasible. The Percutaneous Closure of the Left Atrial Appendage Versus Warfarin Therapy for Prevention of Stroke in Patients With Atrial Fibrillation (PROTECT-AF) trial was the first large randomized clinical trial to test this device. ${ }^{22,23}$ This study was designed to assess the noninferiority of the device against chronic warfarin therapy. The study evaluated 707 patients with non-valvular AF, who were randomly assigned in a 1:2 ratio to either long-term warfarin (international normalized ratio [INR] 2.0-3.0) or the device therapy. Patients allocated to the device group were treated postimplant with warfarin for 45 days to facilitate device endothelialization. Warfarin was discontinued if the follow-up transesophageal echocardiography (TEE) at 45 days showed either complete LAAC or acceptable residual peri-device flow (jet width $\leq 5 \mathrm{~mm}$ ). After discontinuation of warfarin, clopidogrel and aspirin were given until 6 months of follow-up. After this period, aspirin alone was continued. The control group received warfarin with target INR between 2.0 and 3.0, which was only accomplished in two-thirds of the time despite close INR monitoring. Implant success rate was $91 \%$. After a mean follow-up of 18 months (1.065 patient-years), the primary efficacy (composite end point of stroke, systemic embolism, and cardiovascular death) event rate was similar in both groups (3.0 vs 4.9 events per 100 patient-years). The PROTECT-AF study successfully demonstrated the non-inferiority of the Watchman device compared with standard therapy with warfarin..$^{22} \mathrm{~A}$ substudy of the PROTECT-AF assessing quality-of-life parameters in a subset of 547 patients (361 device and 186 warfarin patients) showed that patients with non-valvular $\mathrm{AF}$ at risk of stroke who underwent LAAC had favorable quality-oflife changes at 12 months vs patients treated with warfarin. A post hoc analysis of the PROTECT-AF and Continuous Access Protocol (CAP) registry assessed the net clinical benefit (NCB) of LAAC combining rates of thromboembolism, intracranial hemorrhage, major adverse events, and death for an objective comparison of LAA device closure vs anticoagulation in AF patients. This study showed that the NCB of LAA device closure is highest for patients at high stroke risk but also showed that the benefit of LAAC 


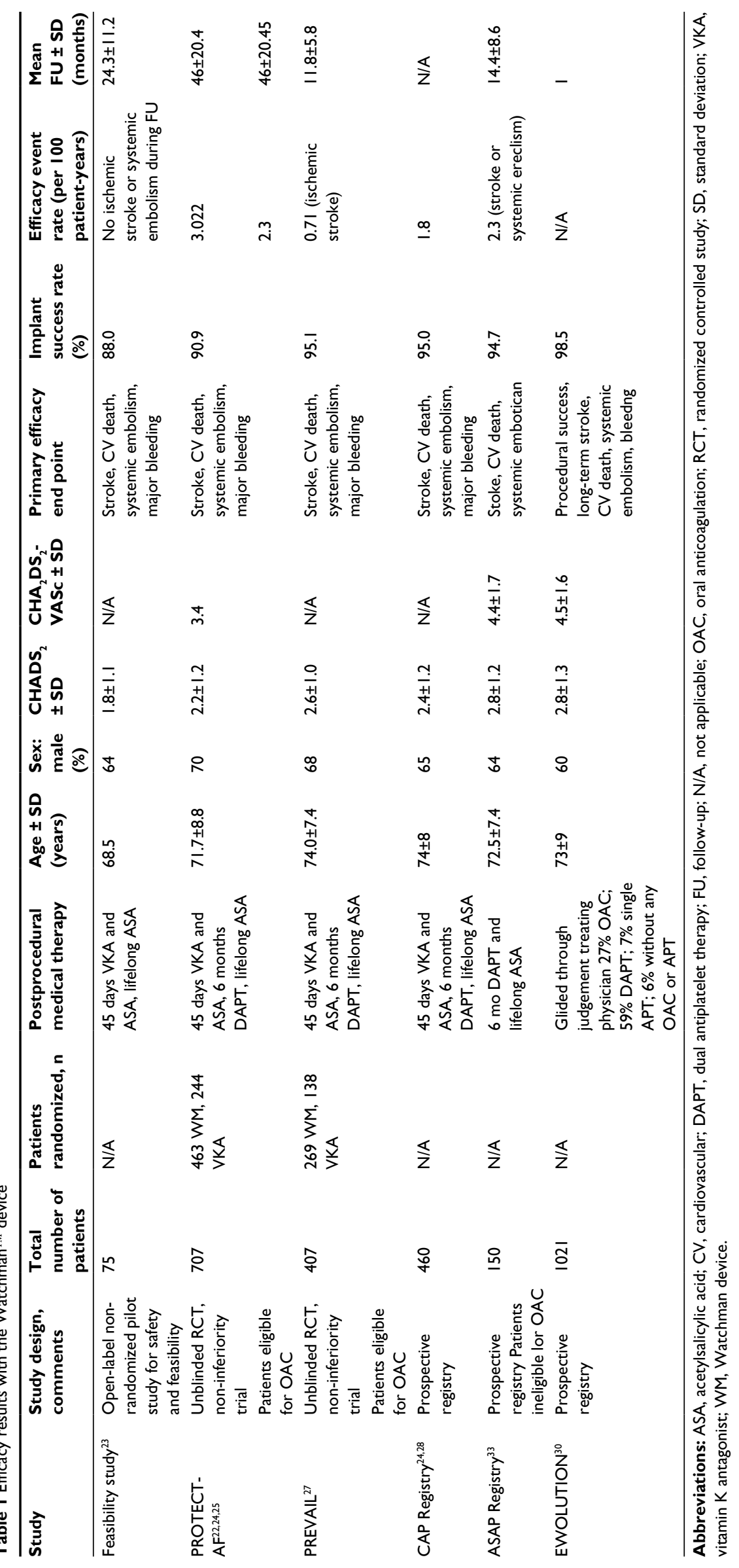


increased over time. In the PROTECT-AF trial, NCB initially favored anticoagulation due to early procedure-related strokes and tamponades, but after 6-9 months, the NCB changed favorably for the device-based intervention, driven mainly by reductions in intracranial bleedings and death in patients who underwent LAAC. This study also showed that operator experience is an important factor to improve the safety and efficacy outcomes because an NCB of LAA device closure in the CAP registry was already achieved after 3 months due to less procedure-related events. ${ }^{24}$

In 2014, the long-term follow-up data of the PROTECTAF trial were published. At mean follow-up of 3.8 years or 2,621 patient-years, the primary efficacy event rate (combined end point of all strokes, cardiovascular or unexplained death, and systemic embolism) was lower in the Watchman group $(2.3 \%)$ than the controls $(3.8 \%)$, which is a $40 \%$ relative risk (RR) reduction, with a $96 \%$ posterior probability of superiority. The reduction in the primary efficacy outcome with Watchman was confirmed through a variety of analyses: intention-to-treat (hazard ratio [HR] 0.61; $P=0.0348$ ), postprocedure (HR 0.52; $P=0.0072$ ), per-protocol (HR 0.50; $P=0.0075$ ), and terminal therapy (HR $0.52 ; P=0.0166)$. In subgroup analysis, only minor differences were seen for sex (HR 0.45 in males vs 1.03 in females), $\mathrm{CHADS}_{2}$ score (HR 0.29 in patients with a $\mathrm{CHADS}_{2}$ of 1 vs 0.99 in patients with a $\mathrm{CHADS}_{2}>1$ ), and AF pattern (HR 0.62 in paroxysmal $\mathrm{AF}, 0.31$ in persistent AF, and 0.84 in permanent AF). No influence was seen in patients with a prior transient ischemic attack (TIA) or stroke (HR 0.66 in patients with a history of TIA/stroke vs 0.61 in patients without a history of TIA/ stroke). Secondary analysis also showed a statistical superiority in all-cause mortality (3.2\% vs $4.8 \%$ ), which is a $34 \%$ $\mathrm{RR}$ reduction (HR $0.66 ; P=0.0379$ ) and $60 \% \mathrm{RR}$ reduction in cardiovascular mortality ( $1.0 \%$ vs $2.4 \%$; HR $0.40 ; P<0.005)$. The favorable outcomes of the device were driven largely by lower rates of hemorrhagic stroke $(0.6 \%$ vs $4.0 \%)$ as well as hemorrhagic stroke-related deaths $(0.4 \%$ vs $3.3 \%)$ but not by ischemic strokes. ${ }^{25}$

According to the PROTECT-AF study, in most studies, a maximal residual jet $<5 \mathrm{~mm}$ around the device is allowed after the procedure. ${ }^{26-28}$ A substudy of the PROTECT-AF indicated that residual peri-device flow into the LAA after percutaneous closure with the Watchman device was observed in up to $32 \%$ of patients at 12-month follow-up. Minimal peri-device flow was not associated with an increased risk of thromboembolism. It needs to be stressed that the event rate in PROTECT-AF was low and therefore this conclusion should be interpreted with caution. ${ }^{29}$

\section{Safety of percutaneous LAAC}

Table 2 provides an overview of literature on safety outcomes with the Watchman device. In the initial feasibility study in 75 patients, two device embolizations were observed, and both devices were recaptured by a transcatheter intervention. After modification of the device, no additional embolizations were seen. There were two cardiac tamponades, one air embolism, and one delivery wire fracture with surgical explantation but no long-term sequelae for the patients. At 6-month follow-up in four patients, thrombus formation was seen on the device that resolved with additional anticoagulation. During a mean follow-up of $740 \pm 341$ days, two patients had a TIA, one of these patients had no apparent thrombus on the device, and there were two non-device-related deaths. ${ }^{23}$

Although in the PROTECT-AF study the device was found at 1,050 patient-years of follow-up to be non-inferior to warfarin in terms of preventing stroke, systemic embolism, and cardiovascular death, its use was accompanied by a higher risk of complications, mostly primarily periprocedural complications such as pericardial effusion and procedural stroke. Primary safety events occurred more frequently in the intervention group than in the control group (7.4 vs 4.4 per 100 patient-years; RR 1.69). A procedure-related stroke was seen in $1.1 \%$ of patients in the intervention group. By contrast with the intervention group, in which $55 \%$ of the primary safety events occurred on the day of the procedure, the events in the control group usually occurred later, with $50 \%$ of events between 45 days and 1 year. Serious pericardial effusion (defined as the need for percutaneous or surgical drainage) with an occurrence of $4.8 \%$ was the most frequent complication in the intervention group. The majority of effusions were resolved with pericardiocentesis. There was no mortality in the group of patients with pericardial effusion, although it prolonged hospital stay compared to the patients without pericardial effusion. Effusion rates declined with investigator experience. Device embolization was seen in three patients $(0.6 \%)$; in one patient, the device was percutaneously removed, while the devices of the other two patients required a surgical procedure, and in one of the these two patients, the aortic valve was damaged requiring concomitant aortic valve replacement. No increased stroke or mortality rates were associated with device embolization. ${ }^{22}$ The long-term follow-up data from the PROTECT-AF show that although warfarin was more beneficial with regard to the primary safety end point early on, this difference diminished at 4 years of follow-up (RR 1.17 for Watchman vs warfarin). ${ }^{25}$ In view of the learning curve effect, it is expected that the number of complications will decrease with more experience. 


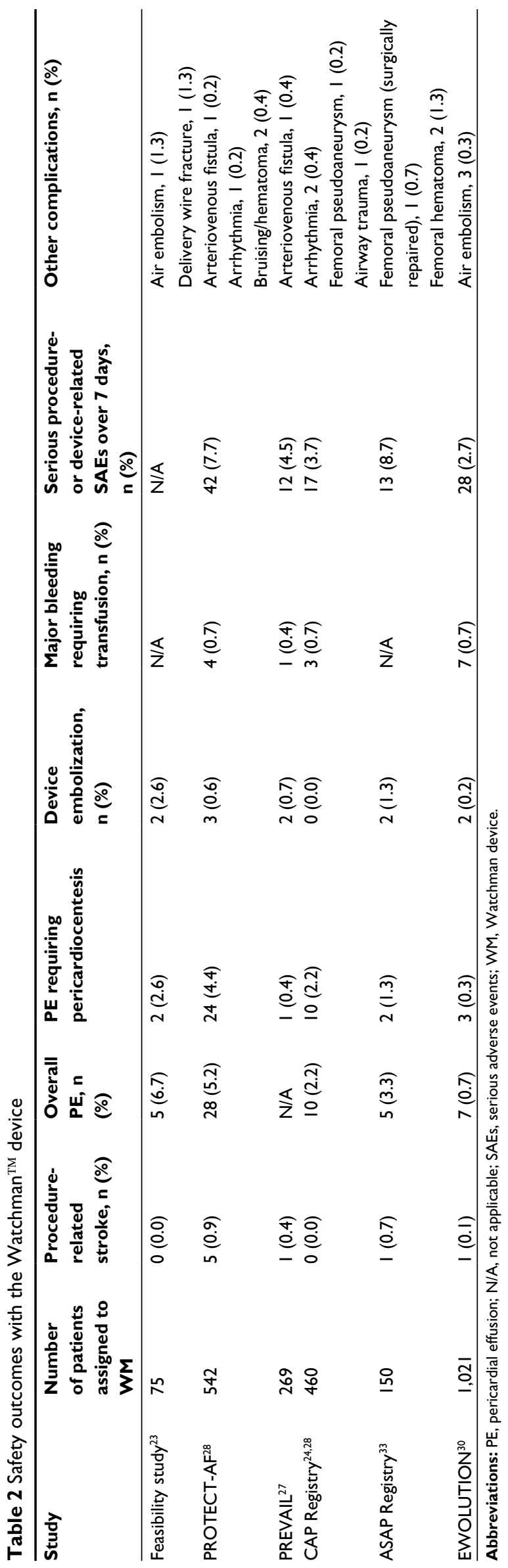

The influence of the operator's experience on the safety of percutaneous LAAC was assessed in the CAP registry. ${ }^{28}$ This was an assessment of safety events in 542 patients from the PROTECT-AF trial who underwent attempted device LAAC and 460 patients from a subsequent nonrandomized registry. The safety end point in this study was bleeding- and procedure-related events (pericardial effusion, stroke, device embolization). A decrease from $7.7 \%$ to $3.7 \%$ was found across the two studies. When comparing event rates from the first and second halves of PROTECT AF and CAP, there was a decrease from $10.0 \%$ to $5.5 \%$ and $3.7 \%$, respectively. Moreover, there was a similar improvement in procedurerelated stroke (from $0.9 \%$ to $0 \%$ ). These data show that complications associated with Watchman implantation are typically seen early in the peri-/postprocedural period and significantly decrease in frequency with operator experience. ${ }^{19}$ These results are supported by the preliminary results of the Prospective Randomized Evaluation of the Watchman LAA Closure Device in Patients with Atrial Fibrillation Versus Long Term Warfarin Therapy (PREVAIL) study. Implant success rate in this study increased to $95 \%$, and safety events (defined as acute occurrence of death, ischemic stroke, systemic embolism, and procedure- or device-related complications requiring major cardiovascular or endovascular intervention) occurred in only $2.2 \%$ of patients. Of interest, a minimum of $20 \%$ of subjects were enrolled at new centers, and $25 \%$ of subjects were enrolled by new operators. ${ }^{27}$

Recently, the clinical data of the multicenter EWOLUTION registry with 1,021 patients were published. The patients in this registry were at high risk of stroke with an average $\mathrm{CHADS}_{2}$ score of $2.8 \pm 1.3$ and a $\mathrm{CHA}_{2} \mathrm{DS}_{2}$-VASc score of $4.5 \pm 1.6$ but also had a moderate-to-high risk of bleeding (an average HAS-BLED score of 2.3 \pm 1.2 ). Almost half of the subjects (45.4\%) had a history of TIA, ischemic stroke, or hemorrhagic stroke, and $62 \%$ of patients were deemed unsuitable for novel OAC therapy by their physician, based on factors such as comorbidities, the inability to adhere to OAC, and bleeding history or high bleeding risk. Nearly one-third of all subjects had a history of major bleeding (31.2\%). In $98.5 \%$ of patients, the device was successfully deployed with no flow or minimal residual flow (defined as $<5 \mathrm{~mm}$ assessed via periprocedural TEE) achieved in $99.3 \%$ of implanted patients. In this large real-world registry, the safety profile of the Watchman device was favorably compared to the previous studies. The most common serious adverse event that occurred within 30 days of the procedure was major bleeding requiring transfusion. In particular, the rate of procedural/device-related strokes, with a rate of $0.1 \%$ in this study, was substantially lower compared to the $0.9 \%$ in PROTECT-AF and $0.4 \%$ in 
PREVAIL. More generally, the incidence of procedure- or device-related serious adverse events over 7 days occurred at a rate of $2.8 \%$, compared with rates of $8.7 \%$ in PROTECT AF, $4.1 \%$ in the CAP registry, and $4.2 \%$ in PREVAIL. The 30-day procedure- or device-related serious adverse event rate was $3.6 \%$, and the overall 30 -day mortality rate was $0.7 \%{ }^{30}$

Finally, many AF patients at highest risk of thromboembolic stroke may also have the greatest risk of hemorrhagic complications of anticoagulation, since some of the risk factors for stroke also increase the risk of bleeding complications, like age, hypertension, and a previous stroke., ${ }^{6,31,32}$ Furthermore, there are patient groups where the patients are unable to sustain chronic oral anticoagulation due to a high bleeding risk/tendency, like patients with hereditary hemorrhagic telangiectasia (Rendu-Osler-Weber disease) or patients with a history of major gastrointestinal bleeding or hemorrhagic stroke. Thus, patients with (relative or absolute) contraindications to oral anticoagulation might benefit from LAAC. This was the objective of the ASA Plavix (ASAP) Registry study, which enrolled patients with contraindications to chronic warfarin treatment. ${ }^{33}$ This prospective registry enrolled 150 patients with non-valvular AF, a CHADS 2 score $\geq 1$, and a contraindication to warfarin use. The mean age of patients was $72.5 \pm 7.4$ years, mean $\mathrm{CHADS}_{2}$ score was 2.8, and $64 \%$ were male. The most common risk factor for stroke was hypertension (94.7\%), and $40 \%$ of patients had previously experienced an ischemic stroke/TIA. History of hemorrhagic/bleeding tendencies (93\%) was the most common reason for warfarin ineligibility. Postimplant, patients were discharged taking clopidogrel for 6 months and aspirin lifelong. The Watchman implantation was successful in 142 of 150 patients $(94.7 \%)$. At mean follow-up of $14.4 \pm 8.6$ months, the combined primary efficacy end point (ischemic stroke, hemorrhagic stroke, systemic embolism, and cardiovascular/ unexplained death) occurred in eight patients, a rate of 4.6 events per 100 patient-years. Stroke was seen in four patients, a rate of 2.3 events per 100 patient-years. In addition, nine patients died, and three had cardiovascular complications. Furthermore, there were five pericardial effusions, of which only two with tamponade required percutaneous drainage, and six instances of device-related thrombus identified by TEE, only one of which resulted in an ischemic stroke. The observed rate of ischemic stroke was $1.7 \%$, corresponding to a $77 \%$ reduction from the expected event rate in patients with a similar $\mathrm{CHADS}_{2}$ score treated with aspirin alone $(7.3 \%)$ and a $64 \%$ reduction vs aspirin and lifelong clopidogrel $(5.0 \%)$. The authors concluded that Watchman implantation without a warfarin transition might be safe and effective in AF patients with contraindications to even short-term OACs.

\section{Clinical utility and future directions}

Current guidelines state that patients with $\mathrm{AF}$ at risk of stroke should be treated with (N)OAC based on assessment of both stroke and bleeding risk, indicated as $\mathrm{CHA}_{2} \mathrm{DS}_{2}$-VASc and HAS-BLED score, respectively. ${ }^{34-36}$ According to the European and Canadian guidelines, percutaneous LAAC may be considered in patients with a (very) high stroke risk and contraindications for long-term OAC with a class IIB recommendation. ${ }^{34,35}$ Worldwide, over 12,000 Watchman devices have been successfully implanted, and roughly the same number of ACPs and Amulet devices (estimates provided by Boston Scientific and St. Jude Medical, respectively). The most important future perspective is to select the patients who would benefit the most from LAAC, with their benefits far outweighing the risks of the procedure. On the contrary, patients who might benefit the most from LAAC, that is, patients with a history of major bleeding, are underrepresented in the available trials. It needs to be stressed that patients in the two randomized trials were on warfarin treatment and had no specific indication for LAAC. The results are therefore difficult to assess for patients with absolute or relative contraindications for VKA therapy.

Long-term follow-up outcome of the EWOLUTION registry may be valuable and provide more knowledge on the safety and efficacy of LAAC in patients ineligible for (N)OAC therapy.

So, the first patient category would be subjects with a history of cerebral bleeding under VKAs and/or NOACs, irrespective of their HAS-BLED score. Second category could include patients with high stroke risk and bleeding risk according to their $\mathrm{CHA}_{2} \mathrm{DS}_{2}$-VASc and HAS-BLED scores, respectively. A third category could be identified in which patients with stroke under adequate VKA or NOAC therapy are included. The final group consists of patients who are noncompliant or unwilling to take VKAs or NOACs. Future studies should illuminate the exact role of LAAC in specific patient categories. ${ }^{37}$

In some centers, the LAAC is combined with AF ablation in one procedure. This is because symptomatic AF is more and more being treated with catheter ablation, since significantly better rhythm outcomes are seen with catheter ablation compared to antiarrhythmic drugs. ${ }^{38-40}$ However, the long-term efficacy of catheter ablation is disappointing, with success rates $<50 \%{ }^{41}$ Therefore, combining LAAO with AF ablation might at least decrease the AF-related symptoms, while decreasing the stroke risk and terminating VKA therapy at the same time. The first studies have shown that this combined procedure can be safely performed. Initial complete LAAO was achieved in $94 \%-100 \%$ of the patients. Despite AF recurrence in $23 \%-44 \%$ of the patients, annual 
stroke risks of $0.5 \%-1.7 \%$ were observed, which were lower than expected based on mean $\mathrm{CHA}_{2} \mathrm{DS}_{2}$-VASc scores of 2.6 and 3.0, respectively. ${ }^{42-44}$

Although the long-term follow-up data of the PROTECTAF have shown that LAAC seems a viable option and might even be superior to warfarin, it is likely that these VKAs are going to be replaced by the NOACs. Until now, no randomized trials have been undertaken to compare NOACs with LAAC devices. Indirect comparisons suggested non-inferiority of LAAC as opposed to NOACs. ${ }^{45-47}$ This assumption however is largely speculative and should be verified in head-to-head randomized controlled studies. ${ }^{48}$

Future trials should not only compare LAAC with the NOACs but also compare closure of the appendage with the device alone vs device closure of the appendage plus anticoagulation. Moreover, various postimplant antithrombotic regimens have been applied in the studies. Future clinical studies should address the appropriate antithrombotic therapy in both immediate postprocedural and long-term phase.

\section{Conclusion}

The long-term efficacy data from PROTECT-AF coupled with safety results of PREVAIL and CAP provide strong evidence that Watchman, the most studied device for LAAC and the only one with randomized and long-term clinical data, may be a viable alternative to chronic warfarin therapy for stroke reduction in non-valvular AF patients.

\section{Disclosure}

The Department of Cardiology receives proctoring fees for training/educational services from Boston Scientific. The authors report no other conflicts of interest in this work.

\section{References}

1. Camm AJ, Kirchhof P, Lip GYH, et al. Guidelines for the management of atrial fibrillation. Eur Heart J. 2010;31(19):2369-2429.

2. Go AS, Hylek EM, Borowsky LH, Phillips KA, Selby JV, Singer DE. Warfarin use among ambulatory patients with nonvalvular atrial fibrillation: the anticoagulation and risk factors in atrial fibrillation (ATRIA) study. Ann Intern Med. 1999;131(12):927-934.

3. Stewart S, Hart CL, Hole DJ, McMurray JJ. Population prevalence, incidence, and predictors of atrial fibrillation in the Renfrew/Paisley study. Heart. 2001;86(5):516-521.

4. Lloyd-Jones D, Adams R, Carnethon M, et al. Heart disease and stroke statistics--2009 update: a report from the American Heart Association Statistics Committee and Stroke Statistics Subcommittee. Circulation. 2009;119(3):e21-e181.

5. Lloyd-Jones DM, Wang TJ, Leip EP, et al. Lifetime risk for development of atrial fibrillation: the Framingham Heart Study. Circulation. 2004; 110(9):1042-1046.

6. Gage BF, Waterman AD, Shannon W, Boechler M, Rich MW, Radford MJ. Validation of clinical classification schemes for predicting stroke. JAMA. 2001;285(22):2864-2870
7. Kannel WB, Wolf PA, Benjamin EJ, Levy D. Prevalence, incidence, prognosis, and predisposing conditions for atrial fibrillation: populationbased estimates. Am J Cardiol. 1998;82(8A):2N-9N.

8. Wolf PA, Abbott RD, Kannel WB. Atrial fibrillation: a major contributor to stroke in the elderly. The Framingham Study. Arch Intern Med. 1987;147(9):1561-1564.

9. Wolf PA, Abbott RD, Kannel WB. Atrial fibrillation as an independent risk factor for stroke: the Framingham Study. Stroke. 1991;22(8): 983-988.

10. Björck S, Palaszewski B, Friberg L, Bergfeldt L. Atrial fibrillation, stroke risk, and warfarin therapy revisited: a population-based study. Stroke. 2013;44(11):3103-3108.

11. Marini C, De Santis F, Sacco S, et al. Contribution of atrial fibrillation to incidence and outcome of ischemic stroke: results from a populationbased study. Stroke. 2005;36(6):1115-1119.

12. Lamassa M, Di Carlo A, Pracucci G, et al. Characteristics, outcome, and care of stroke associated with atrial fibrillation in Europe: data from a multicenter multinational hospital-based registry (The European Community Stroke Project). Stroke. 2001;32(2):392-398.

13. Asinger RW, Koehler J, Pearce LA, et al. Pathophysiologic correlates of thromboembolism in nonvalvular atrial fibrillation: II. Dense spontaneous echocardiographic contrast (The Stroke Prevention in Atrial Fibrillation [SPAF-III] study). JAm Soc Echocardiogr. 1999;12: 1088-1096.

14. Blackshear JL, Odell JA. Appendage obliteration to reduce stroke in cardiac surgical patients with atrial fibrillation. Ann Thorac Surg. 1996; 61(2):755-759.

15. Goldman ME, Pearce LA, Hart RG, et al. Pathophysiologic correlates of thromboembolism in nonvalvular atrial fibrillation: I. Reduced flow velocity in the left atrial appendage (The Stroke Prevention in Atrial Fibrillation [SPAF-III] study). J Am Soc Echocardiogr. 1999; 12(12):1080-1087.

16. Odell JA, Blackshear JL, Davies E, et al. Thoracoscopic obliteration of the left atrial appendage: potential for stroke reduction? Ann Thorac Surg. 1996;61(2):565-569.

17. Sievert H, Lesh MD, Trepels T, et al. Percutaneous left atrial appendage transcatheter occlusion to prevent stroke in high-risk patients with atrial fibrillation: early clinical experience. Circulation. 2002;105(16): 1887-1889.

18. Omran H, Hardung D, Schmidt H, Hammerstingl C, Lüderitz B. Mechanical occlusion of the left atrial appendage. J Cardiovasc Electrophysiol. 2003;14(9 Suppl):S56-S59.

19. Tzikas A, Shakir S, Gafoor S, et al. Left atrial appendage occlusion for stroke prevention in atrial fibrillation: multicentre experience with the AMPLATZER Cardiac Plug. EuroIntervention. 2016;11(10):1170-1179.

20. Bartus K, Bednarek J, Myc J, et al. Feasibility of closed-chest ligation of the left atrial appendage in humans. Heart Rhythm. 2011;8(2): 188-193.

21. Bartus K, Han FT, Bednarek J, et al. Percutaneous left atrial appendage suture ligation using the LARIAT device in patients with atrial fibrillation: initial clinical experience. J Am Coll Cardiol. 2013;62(2): 108-118.

22. Holmes DR, Reddy VY, Turi ZG, et al. Percutaneous closure of the left atrial appendage versus warfarin therapy for prevention of stroke in patients with atrial fibrillation: a randomised non-inferiority trial. Lancet. 2009;374(9689):534-542.

23. Sick PB, Schuler G, Hauptmann KE, et al. Initial worldwide experience with the WATCHMAN left atrial appendage system for stroke prevention in atrial fibrillation. J Am Coll Cardiol. 2007;49(13):1490-1495.

24. Gangireddy SR, Halperin JL, Fuster V, Reddy VY. Percutaneous left atrial appendage closure for stroke prevention in patients with atrial fibrillation: an assessment of net clinical benefit. Eur Heart J. 2012;33(21):2700-2708.

25. Reddy VY, Sievert H, Halperin J, et al. Percutaneous left atrial appendage closure vs warfarin for atrial fibrillation: a randomized clinical trial. JAMA. 2014;312(19):1988-1998.

26. Alli O, Doshi S, Kar S, et al. Quality of life assessment in the randomized PROTECT AF trial of patients at risk for stroke with non-valvular atrial fibrillation. J Am Coll Cardiol. 2013;61(17):1790-1798. 
27. Holmes DR, Kar S, Price MJ, et al. Prospective randomized evaluation of the Watchman Left Atrial Appendage Closure device in patients with atrial fibrillation versus long-term warfarin therapy: the PREVAIL trial. J Am Coll Cardiol. 2014;64(1):1-12.

28. Reddy VY, Holmes D, Doshi SK, Neuzil P, Kar S. Safety of percutaneous left atrial appendage closure: results from the Watchman Left Atrial Appendage System for Embolic Protection in Patients with AF (PROTECT AF) clinical trial and the Continued Access Registry. Circulation. 2011;123(4):417-424.

29. Viles-Gonzalez JF, Kar S, Douglas P, et al. The clinical impact of incomplete left atrial appendage closure with the Watchman Device in patients with atrial fibrillation: a PROTECT AF (Percutaneous Closure of the Left Atrial Appendage Versus Warfarin Therapy for Prevention of Stroke in Patients With Atrial Fibrillation. JAm Coll Cardiol. 2012;59(10):923-929.

30. Boersma LVA, Schmidt B, Betts TR, et al. Implant success and safety of left atrial appendage closure with the WATCHMAN device: periprocedural outcomes from the EWOLUTION registry. Eur Heart J. Epub 2016 Jan 27.

31. Lip GYH, Nieuwlaat R, Pisters R, Lane DA, Crijns HJGM. Refining clinical risk stratification for predicting stroke and thromboembolism in atrial fibrillation using a novel risk factor-based approach: the euro heart survey on atrial fibrillation. Chest. 2010;137(2):263-272.

32. Pisters R, Lane DA, Nieuwlaat R, de Vos CB, Crijns HJGM, Lip GYH. A novel user-friendly score (HAS-BLED) to assess 1-year risk of major bleeding in patients with atrial fibrillation: the Euro Heart Survey. Chest. 2010;138(5):1093-1100.

33. Reddy VY, Möbius-Winkler S, Miller MA, et al. Left atrial appendage closure with the Watchman device in patients with a contraindication for oral anticoagulation: the ASAP study (ASA Plavix Feasibility Study With Watchman Left Atrial Appendage Closure Technology). JAm Coll Cardiol. 2013;61(25):2551-2556.

34. John Camm A, Lip GYH, De Caterina R, et al. 2012 focused update of the ESC Guidelines for the management of atrial fibrillation. Eur HeartJ. 2012;33(21):2719-2747.

35. Verma A, Cairns JA, Mitchell LB, et al. 2014 focused update of the Canadian Cardiovascular Society Guidelines for the management of atrial fibrillation. Can J Cardiol. 2014;30(10):1114-1130.

36. January CT, Wann LS, Alpert JS, et al. 2014 AHA/ACC/HRS Guideline for the management of patients with atrial fibrillation. J Am Coll Cardiol. 2014;64(21):e1-e76.
37. John Camm A, Colombo A, Corbucci G, Padeletti L. Left atrial appendage closure: a new technique for clinical practice. Heart Rhythm. 2014; 11(3):514-521

38. Oral H, Pappone C, Chugh A, et al. Circumferential pulmonary-vein ablation for chronic atrial fibrillation. $N$ Engl J Med. 2006;354(9): 934-941.

39. Pappone C, Augello G, Sala S, et al. A randomized trial of circumferential pulmonary vein ablation versus antiarrhythmic drug therapy in paroxysmal atrial fibrillation: the APAF Study. J Am Coll Cardiol. 2006; 48(11):2340-2347.

40. Stabile G, Bertaglia E, Senatore G, et al. Catheter ablation treatment in patients with drug-refractory atrial fibrillation: a prospective, multicentre, randomized, controlled study (Catheter Ablation For The Cure Of Atrial Fibrillation Study). Eur Heart J. 2006;27(2):216-221.

41. Weerasooriya R, Khairy P, Litalien J, et al. Catheter ablation for atrial fibrillation: are results maintained at 5 years of follow-up? $\mathrm{J} \mathrm{Am} \mathrm{Coll}$ Cardiol. 2011;57(2):160-166.

42. Swaans MJ, Post MC, Rensing BJWM, Boersma LVA. Ablation for atrial fibrillation in combination with left atrial appendage closure: first results of a feasibility study. J Am Heart Assoc. 2012;1(5):e02212.

43. Phillips KP, Walker DT, Humphries JA. Combined catheter ablation for atrial fibrillation and Watchman ${ }^{\circledR}$ left atrial appendage occlusion procedures: five-year experience. J Arrhythm. 2016;32(2):119-126.

44. Alipour A, Swaans MJ, van Dijk VF, et al. Ablation for atrial fibrillation combined with left atrial appendage closure. JACC Clin Electrophysiol. 2015;1(6):486-495.

45. Messori A, Maratea D, Fadda V, Trippoli S. New and old anti-thrombotic treatments for patients with atrial fibrillation. Int J Clin Pharm. 2013; 35(3):297-302

46. Messori A, Fadda V, Maratea D, Trippoli S. Left atrial appendage occlusion devices versus pharmacological agents for stroke prevention in atrial fibrillation: testing the noninferiority margins. JACC Cardiovasc Interv. 2014;7(8):942-943.

47. Messori A, Trippoli S. Left atrial appendage occlusion devices versus pharmacological agents for stroke prevention in atrial fibrillation. $\mathrm{JAm}$ Coll Cardiol. 2015;66(18):2056-2058

48. Parashar A, Agarwal S, Bajaj NS, Tuzcu EM, Kapadia SR. Reply: left atrial appendage occlusion devices versus pharmacological agents for stroke prevention in atrial fibrillation: testing the noninferiority margins. JACC Cardiovasc Interv. 2014;7(8):943.
Medical Devices: Evidence and Research

\section{Publish your work in this journal}

Medical Devices: Evidence and Research is an international, peerreviewed, open access journal that focuses on the evidence, technology, research, and expert opinion supporting the use and application of medical devices in the diagnosis, monitoring, treatment and management of clinical conditions and physiological processes. The identification of novel

\section{Dovepress}

devices and optimal use of existing devices which will lead to improved clinical outcomes and more effective patient management and safety is a key feature. The manuscript management system is completely online and includes a quick and fair peer-review system. Visit http://www. dovepress.com/testimonials.php to read real quotes from authors. 